\title{
CEsifo \\ WORKING

\section{Sham Litigation, Delayed Tax Payment and Evasion: The Role of Informal Credit Market}

Sugata Marjit, Suryaprakash Mishra, Sandip Mitra 


\section{Impressum:}

CESifo Working Papers

ISSN 2364-1428 (electronic version)

Publisher and distributor: Munich Society for the Promotion of Economic Research - CESifo

$\mathrm{GmbH}$

The international platform of Ludwigs-Maximilians University's Center for Economic Studies and the ifo Institute

Poschingerstr. 5, 81679 Munich, Germany

Telephone +49 (0)89 2180-2740, Telefax +49 (0)89 2180-17845, email office@cesifo.de

Editor: Clemens Fuest

www.cesifo-group.org/wp

An electronic version of the paper may be downloaded

- from the SSRN website: www.SSRN.com

- from the RePEc website: www.RePEc.org

- from the CESifo website: www.CESifo-group.org/wp 


\title{
Sham Litigation, Delayed Tax Payment and Evasion: The Role of Informal Credit Market
}

\begin{abstract}
We model the interaction between the informal credit market and the act of tax collection by the government; in presence and functioning of the informal credit market, the agents (the tax paying firms) engage in false or sham litigation and deferred tax payments. During the litigation period they earn higher return, higher than the punishment rates charged by the government. Proportion of false claims increases with size. In this context we get a result that contradicts conventional wisdom in tax evasion literature whereby higher tax rate actually leads to greater compliance and tax rate acts as a policy instrument even when in the standard case it does not affect evasion. We propose part-payment of the disputed amount by the tax paying firm to the government as a possible solution to the problems of excessive litigation against the government, delayed tax payments and evasion; it also has a positive impact on the tax collection of the government. Finally, we also attempt to explain as to why and how the government policies may be intentionally designed to foster the informal sector.
\end{abstract}

JEL-Codes: H250, H260, H320, K340, K410, K420.

Keywords: delayed tax payment, evasion, sham litigation, informal credit market.

Sugata Marjit

Indian Institute of Foreign Trade \& CSSSC

Calcutta / India

marjit@gmail.com

\author{
Suryaprakash Mishra \\ National Law University \\ Delhi / India \\ misra.suryaprakash@gmail.com
}

\author{
Sandip Mitra \\ Indian Statistical Institute \\ Calcutta / India \\ sandipisi@gmail.com
}

Sugata Marjit is indebted to the Universities of Queensland and Konstanz, IGIDR Mumbai and CES-ifo Munich for hospitality. Discussions with Arye Hillman, Orazio Attansio and Vivekananda Mukherjee have been quite rewarding. The financial assistance of the RBI Endowment at CTRPFP at CSSSC is duly acknowledged. The usual disclaimer applies. 


\section{Section 1: $\underline{\text { Introduction }}$}

Adequate collection of tax revenue is an important pre-condition for undertaking public expenditure. In a typical developing country, state-sponsored welfare programs, public investment in health, education, infrastructure etc. are helped much if the government manages to earn decent amount of revenue through taxation. Else, they have to depend on borrowings, expanding public debt, raising cost of private investment and possibly getting into a debt trap. Revenue generation through taxes looks structurally different between a developed and a developing country. Though the governments' incentives for tax enforcement can be crucial to both tax enforcement and tax capacity of a country ${ }^{2}$. It is well known that the share of direct taxes is typically lower in a poor country. It is also well accepted that tax evasion is far more serious a problem in a developing country as it is linked with corruption. Such issues have been discussed time and again in various contexts. A huge literature exists and interested readers may have a look at a recent compendium by Congleton and Hillman (2015). Specifically for tax evasion problem in the context of developing countries one may refer to Dasgupta and Mookherjee (1998), Marjit and Shi (1998), Marjit, Mukherjee and Mukherjee (2000), Loukas et al. (2015) etc. For issues related to corruption one could look at Marjit, Seidel and Thum (2016), Marjit, Mukherjee and Mukherjee (2000), Marjit, Rajeev and Mukherjee (2000), Olken and Pande (2011), Tanzi and Davoodi (2000) etc.

One issue that is not discussed seriously is the role of credit market imperfection and existence of informal credit market and how they interact with the act of tax collection by the government. These may actually induce agents to engage in false or sham litigations and defer their tax payments. There is a huge contrast in the functioning of the developed economies in comparison to the developing ones. In developed countries, majority of the population is in the formal sector whereas in the developing countries the opposite is true. In the developing world, the informal sector has a huge impact on the overall functioning of the economy. For the above reason, there is a gap in the literature (pertaining to the developed countries) regarding the role of the dynamics generated by the informal sector on the agents (in both the formal as well as the informal sectors) and hence the resulting polies by the government(s), and this gap is the motivation for our paper. Independent of bureaucratic corruption that we often talk about such as bribery and harassment, the idea that investment in informal credit market promises a substantial premium on the formal sector rate of return and hence may lead to deferred tax

\footnotetext{
${ }^{2}$ Xiaoguang S, C. (2017) through evidence from natural experiment in China suggests that revenue loss incentivises the local government to resort to tougher tax enforcement.
} 
payment, are seldom brought to the focus. Thus, even if we abstract from the unholy alliance between the auditor and the tax payer, inability of the government to record informal sale in the goods market etc., revenue collection might still suffer because the government may have to face excessive litigation against tax claims.

In a recent study [Marjit and Mitra (2015)] such a problem was identified and analysed based on a small sample of return filing firms who engaged tax lawyers to challenge the tax claims by the government in the state of West Bengal, India. This was a small indicative study done with the help of the lawyers who actually fight these cases for their clients. We use our experiences in the study to identify a new avenue of tax evasion. Many such claims are eventually negotiated and settled but not before the firms have made a killing in the informal credit market since informal interest rate typically is much higher than formal sector interest rates. Typically, penalty on deferred payment was almost equivalent to the equilibrium borrowing rate in the formal or legal market which was far lower than the rate of interest in the informal sector. The above study tried to look at the size-distribution of clients who appeal against tax claims and wait for renegotiations, the potential loss in tax-revenue and the strategy of an upfront fee to counter such malpractice. The data-base was tax-files made available by few lawyers. Tendency for excessive litigations against tax claims are aggravated by the alternative higher rate of return in the informal sector. The Following emerged in this context: (a). It was observed from the data collected from a few lawyers that a significant section of tax payers (about $30-40 \%$ ) opt to go for disputes and 70-80\% out of them are found to be gainers consistently (source: tax lawyers' information), and (b). The proportion of dispute cases increase with turnover implying that large firms opt for dispute more than small (see graph below).

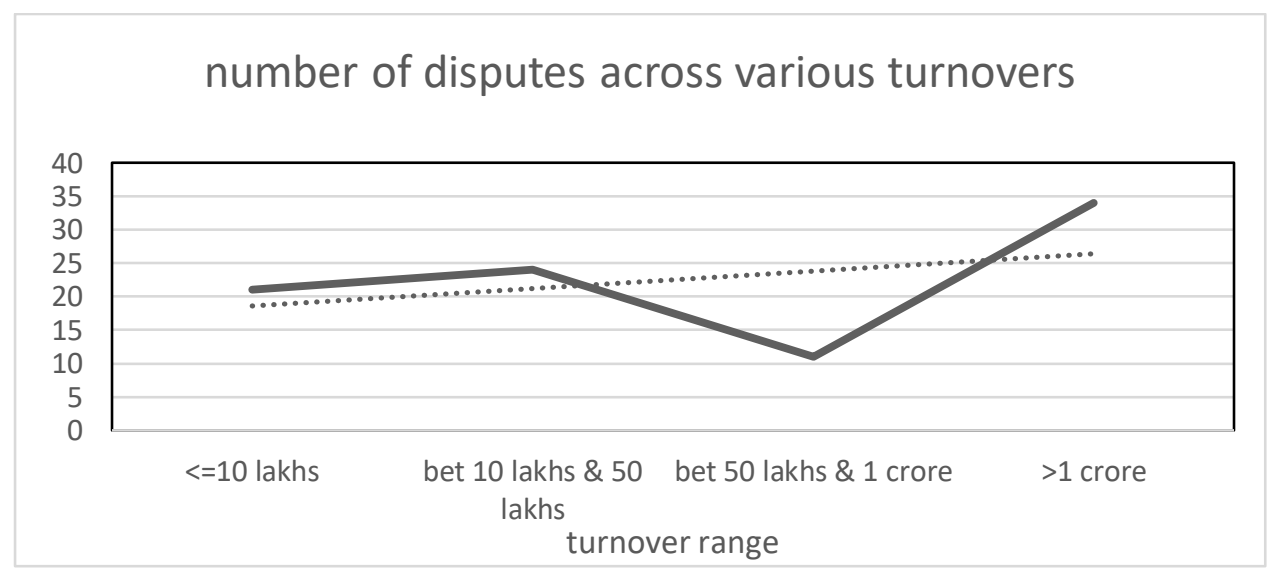

Figure 1: Number of disputes across various turnovers

Source: Marjit \& Mitra (2015) 
The study attempted to answer the question as to whether the firms dispute the tax amount and engage in false litigation as a matter of strategy. Based on investment two types of defaulters, namely, honest and dishonest were identified. The honest tax payer disputed the tax amount and litigated against the government in self-defence in case(s) of improper imposition of taxes and invested the disputed tax amount in the formal sector (banks etc.) at a lower interest rate, whereas the dishonest ones disputed the tax amount and litigated against the government in expectation of huge profit from investment of the disputed tax amount in the unregulated informal sector (with interest rate ranging from 3 to $5 \%$ per month). As a matter of practice, government officials often fail to screen such dishonest taxpayers when they penalize and charge higher tax later on, and thus, the honest taxpayers also get penalized. We argue that an upfront payment proportional to the disputed tax amount may increase the gain of the government and generate more incentive against tax default. Papers by Kenyon (2008), Capasso and Jappelli (2013), Blackburn, Bose, and Capasso (2012) etc. have tried to relate financial development to the size of underground economy. But none actually focuses on the relationship between large informal credit-market driven incentives to litigate against tax claims of the government. Greater financial development has been shown to reduce the size of the underground economy. Tax evasion is one mechanism to generate the cash flow needed to finance production and investment when access to bank or equity finance is restricted. But our mechanism is novel as it shows higher informal interest rates will instigate firms to engage in false but legal battles to pop up their profits. Government is institutionally restricted to charge interest penalty based on informal transactions and the possibility of arbitrage will lead to deferred and unsettled claims.

Our paper is strikingly different from the ones where existence of informal product market induces firms to engage in tax-avoiding transactions. Hence, they make a choice between transacting legally and extra-legally in the product market, how much revenue to report and how much to hide etc. But our statistical evidence which provides the starting point of this theoretical work, deals with formal sector firms who, sell only in the formal markets and are registered entities. Even if they do not misreport their sales, they can still defer the tax payment and in the end make an additional profit. They may engage in informal sales or production, but they can still engage in investing in the informal credit market. If they report sales they have to pay tax. When they do not have any informal market to sell their goods, they would still engage in effective tax-avoidance by investing in the informal market which thrives on unrecorded transactions and unregistered firms. Thus, tax-evasion by firms in this model 
does not have to follow the standard mechanism as generally assumed in the literature. Even if the government could perfectly monitor sales outside the legal domain of operations and hence the firms can never get away by not paying taxes, they would still like to under-invoice their sales by litigating against government. They may eventually pay entire tax with penalty, but they would earn profit in the meantime. A firm selling in the market A will invest as a creditor in market B where it does not have any interest in sales. Contribution in the domain of sham litigations never focused on the tax issue and role of backdoor investment during litigations. Typically false litigations have featured in patent related cases in USA involving Anti-Trust Bureau of FTC, but never have been dealt with in the context of alternative higher returns Klein (1989).

In our analytical model we provide a formulation to estimate informal interest rate from an equilibrium relationship that determines participation in informal market by firms. This is a way of determining informal rates of return which are usually explored through primary surveys. Such relationship allows us to impute such rates in terms of publicly available information.

The paper is structured as follows. Section 2 provides the basic model. Section 3 introduces the informal credit market. Section 4 provides a counter mechanism to contain false litigation. Section 5 discusses welfare and policy in light of the informal sector and the last section concludes.

\section{Section 2: Model}

Consider a firm which has sold goods and earned income of $x$ and is liable to pay tx as tax to the government; we assume proportional taxation (throughout the paper). But it contemplates false litigation to appeal against the tax claim of $t x$ by the government. The suit is filed now and the verdict comes tomorrow. The firm claims that it has earned $\tilde{x}<x$. There is a probability $\rho$ with which the verdict goes against the firm. Even if $x$ is the correct figure, we assume that in the legal battle there are noises in the judiciary process and the judge can make an error of judgement. Hence, with probability $\rho$, the firm pays $\rho t(x-\tilde{x})$ plus an interest $\operatorname{cost} r$ and a penalty $f>0$ and there is a legal $\operatorname{cost} \mathcal{L}>0$. This is the benchmark model with no possibility of earning informal interest rate.

The maximization problem faced by the tax paying firm is given by,

$$
V(\tilde{x})=(x-t \tilde{x})(1+r)-\rho t(x-\tilde{x})(1+r+f)-\mathcal{L}
$$


Let $\rho=\frac{(x-\tilde{x})}{x} ; \tilde{x} \in[0, x] . \rho=0$ for $\tilde{x}=x ; \rho=1$ for $\tilde{x}=0$ and $\rho$ declines as $\tilde{x}$ goes up.

Thus the above objective function can be written as following,

$$
V(\tilde{x})=(x-t \tilde{x})(1+r)-t \frac{(x-\tilde{x})^{2}}{x}(1+r+f)-\mathcal{L}
$$

Differentiating and optimizing gives the following,

$$
\begin{aligned}
& (x-\tilde{x})=\frac{(1+r) x}{2(1+r+f)} \\
\Rightarrow & \tilde{x}=x\left(1-\frac{(1+r)}{2(1+r+f)}\right)
\end{aligned}
$$

A profit maximizing tax-paying firm would choose between taking up false litigation against the government for the tax claims or agreeing to the tax claims and paying the same (the benchmark case and no litigation), by comparing its payoffs under the two situations. Which leads us to,

$$
V(\tilde{x})-\pi(x)=\frac{t x(1+r)^{2}}{4(1+r+f)}-\mathcal{L}=\phi(x)-\mathcal{L} ; \phi^{\prime}>0
$$

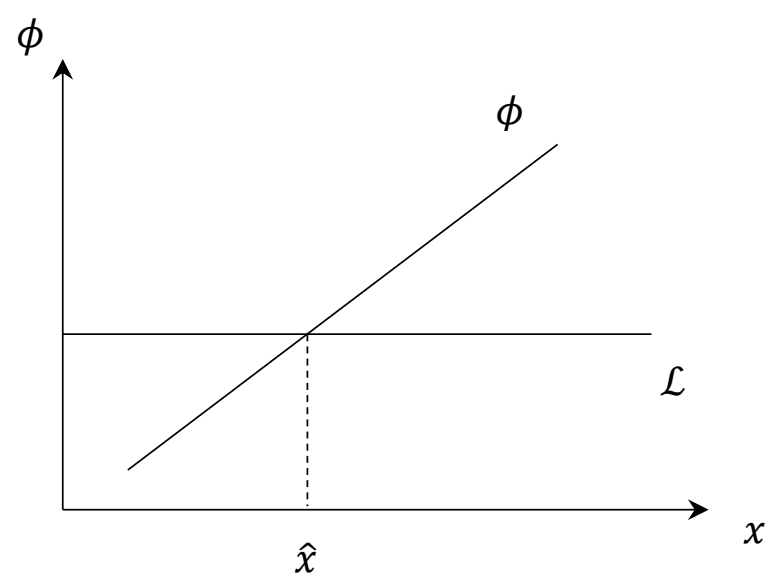

Figure 2: Incentives for false litigation

Proposition 1: Given $t, r, f$ and $\mathcal{L}$ there exists a critical level of turnover, i.e., $\hat{x}$, such that $\forall x<\hat{x}$ firms will not engage in false litigation against the government and $\forall x>\hat{x}$ firms will engage in false litigation against the government.

Proof of Proposition 1: Please see the above analysis in section 2 and figure 2. $\quad$ Q.E.D. 


\section{Section 3: False Litigation with Informal Credit Market}

We now consider a case where the informal rate of return $R>r$. The firm in the formal sector invests $(x-\tilde{x})$ to earn $R$, claims $\tilde{x}$ to be its true income and invests $\tilde{x}(1-t)$ in the formal sector to earn $r$. The firms which belong to the informal sector, can not borrow from banks (due to lack of assets as collateral which are required in order to avail loans); they borrow from the formal sector firms at a higher rate of $R$.

The objective function of the formal sector firm (the tax paying firm) investing (lending) in the informal sector would be as follows,

$$
V(\tilde{x})=(x-\tilde{x})(1+R)+\tilde{x}(1-t)(1+r)-t \frac{(x-\tilde{x})^{2}}{x}(1+r+f)-\mathcal{L}
$$

Here $R>r$ provides the additional incentive for false litigation. Finally have,

$$
\begin{aligned}
& (x-\tilde{x})=\frac{(R-r) x}{2 t(1+r+f)}+\frac{(1+r) x}{2(1+r+f)} \\
& \tilde{x}=x\left(1-\frac{(R-r)+t(1+r)}{2 t(1+r+f)}\right)
\end{aligned}
$$

Similarly, as above,

$$
V(\tilde{x})-\pi(x)=\phi(x)-\mathcal{L} ; \phi^{\prime}>0 .
$$

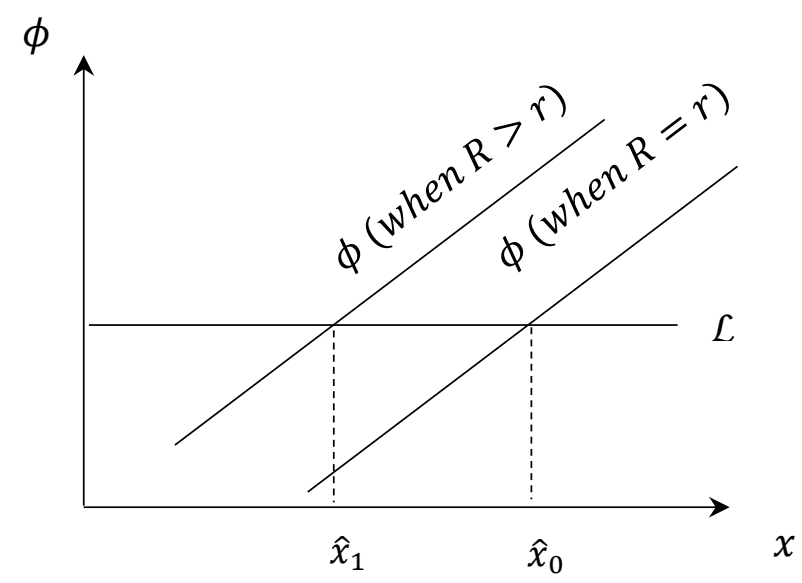

Figure 3: Rate of return differential and the incentive for false litigation 
Proposition 2: In the event of presence and functioning of the informal credit market, more firms (including the firms with smaller turnover) will challenge the tax claims and engage in false litigation against the government.

Proof of Proposition 2: Please see the above analysis in section 3 and figure $3 . \quad$ Q.E.D.

In the evasion literature, there is a divergence between the theoretical results and empirical findings; most of the theoretical results show that reported income is an increasing function of tax rate while empirical findings say the opposite. Two seminal theoretical contributions have been Allingham and Sandmo (1972) and Yitzhaki (1974). Papers analysing other issues on tax compliance behaviour are Dhami and al-Nowaihi (2007), Slemrod (2007), Slemrod \& Yitzhaki (2002) etc. However, the tax payers' behavioural response is a function of the degree of intervention by the tax authorities ${ }^{3}$. For a survey on the tax rate and tax evasion, one may refer to Freire-Seren \& Panades (2013), which focusses on policy debates claiming that evasion is an increasing function of the tax rate. However, theory does not have a clear prediction on this.

It is well known in the tax evasion literature that when penalty is on total tax evaded rather than on total income misreported, tax rate does not affect the optimal deviation as $t$ cancels out in the first order condition. Here we show that as $t$ increases the extent of false claim will be lower, i.e., better reporting by the firms reflecting greater compliance. In the usual cases, discussed in the evasion literature, the $(x-\tilde{x})(1+R)$ term, which is due to the presence and functioning of the informal credit market, is missing. Thus this extra benefit compensates the extra net marginal cost for non-compliance relative to the usual case, reflecting higher attempted evasion. Thus the level of compliance will be less for any given tax rate in this case. But now tax rate is an effective policy instrument unlike in the standard case. Higher rate of tax actually increases that extra net marginal cost of non-compliance, which would be zero in the usual case. Therefore, higher tax will imply greater compliance in terms of the lower value of false litigation.

\footnotetext{
${ }^{3}$ Slemord \& Keen (2017) analyse optimal intervention by tax administration and develop a summary measure namely "enforcement elasticity of tax revenue" to measure the behavioural response to such intervention much as the elasticity of the taxable income measures the response to the tax rate.
} 
Also note that $\rho=\frac{x-\tilde{x}}{x}=\frac{t x-t \tilde{x}}{t x}$, i.e., it does not matter as to how we model $\rho$, whether it is based on deviation of income or taxes. Also, this generates a quadratic cost function $\frac{t}{x}(x-\tilde{x})^{2}$ endogenously, usually a common assumption in tax evasion literature.

Proposition 3: There exists a computable relationship for determining the informal rate of return, i.e., $R$.

Proof of Proposition 3: Using equation (6), we get a computable relationship for determining $R$, which is as follows,

$$
R=2 t(1+r+f)\left\{1-\frac{\tilde{x}}{x}\right\}+r(1+t)-t \quad \text { Q.E.D. }
$$

Given that we have data on extent of litigation $(x-\tilde{x})$, tax rate, turnover, formal interest rate and $f$, we can determine $R$. In fact in the statistical report of Marjit and Mitra (2015) we have data on all the above mentioned variables and can determine $R$. This is an alternative way to determine informal rates from surveys or direct empirical verification.

We have just established above that the informal sector's rate of return lures the firms (of smaller turnovers as well) to engage in false litigation against the government regarding the tax claims and invest in the informal sector. Thus, the fact that the informal rate of return surpasses the formal rate of return, i.e., $R>r$, ultimately leads to aggravation of both the problem of and also the ones due to sham litigation.

In an annual document of the government of India this year, the Economic Survey (2017 -18 ), roughly a chapter has been devoted to the dynamics of the activity of litigation. The following lines give the crucial highlights. The Indian government's efforts to make business and commerce easy have been widely well received. The other logical steps with context to the ease of doing business that the government ought to take is addressing the problems of pendency, delays and backlogs of cases with the adjudicating authorities, namely, the tribunal and the courts. The said problems, which are basically law and economics issues, are detrimental for the overall economic activity of the country as they hamper dispute resolution and enforceability of contracts, dampen/discourage investments, stall projects, adversely impact the tax collection/revenues, stress the tax payers and escalate the legal costs.

Delays and pendency in the case of tax litigation in context to India is due to the government's persistence with litigation despite low success rates at almost every stage of the appellate process; the pendency of the tax cases at an average, is about 6 years. The success 
rate of the government at all three level of appeal, i.e., Appellate Tribunals, High Courts, and Supreme Court - for both direct and indirect tax litigation is below 30\%, while in some cases it is about $12 \%$ (the government loses about over $65 \%$ of its cases). Intertemporal trend hints that the success rate of the government has been on the decline while that of the assessees has been on the rise (Economic Survey of India, 2017-18). For more detailed treatment the interested readers may have a look at the Economic Survey of India, 2017-18.

Apart from the above problems, sham litigation leads to other problems that are undesirable from the societal welfare perspective, namely, gain of the formal sector firms at the cost of the informal sector firms, enhancement of the informal activity and diversion of resources to the process of litigation which could be directed to alternative $\&$ more productive ends.

Literature on the link between judiciary and business and commercial activities [North (1990), Engerman and Sokoloff (2000), Acemoglu, Johnson and Robinson (2001), Rodrik, Subramanian and Trebbi (2004), Acemoglu and Johnson (2005), La Porta et al. (1998, 1999), Kapur and Mehta (2007), Kapur, Mehta and Vaishnav (2017) and Chemin (2012)] hints that clarity and certainty in legislative and executive regimes supported by an efficient judiciary is a necessary prerequisite for business and commerce and hence, the overall economic activity.

While the Economic survey of India (2017-18) proposes certain solutions such as coordinated action between the government and the judiciary (and many more) to address the judicial delays and boost economic activity, we propose a mechanism which will reduce false litigation to some extent, thereby, also reducing the problems which are entailed due to falsa litigation (highlighted above). The next section contains our proposition.

\section{Section 4: $\underline{\text { A Counter - Measure: Upfront Tax Payment }}$}

In this section we propose a mechanism which will reduce false litigation to some extent. Suppose the government insists on an upfront payment of litigated amount and promises to return it with interest and penalty/fine if the claim by the government is nullified in court of law; the same holds for the firms as well, i.e., if the verdict goes against them, then they must pay the government the remaining tax amount along with the interest and penalty/fine on the same. We assume symmetric penalty for both the parties (firms and the government). This actually weakens the strategy of private firms which provide utilities such as electricity. Calcutta Electric Supply Corporation, a private monopoly, insists on upfront payment of 
disputed amount until the matter is settled. In this case a fraction, $\beta$, of the disputed amount has to be paid upfront. This alters the objective function of the tax paying firm as below,

$$
\begin{gathered}
V(\tilde{x})=[x-\tilde{x}-\beta t(x-\tilde{x})](1+R)+\tilde{x}(1-t)(1+r)-\left(\frac{(x-\tilde{x})}{x}\right)(1-\beta) t(x-\tilde{x})(1+r+ \\
f)+\left(1-\left(\frac{(x-\tilde{x})}{x}\right)\right) \beta t(x-\tilde{x})(1+r+f)-\mathcal{L}
\end{gathered}
$$

Optimizing the above we get,

$$
\begin{aligned}
& \left(x-\tilde{x}_{\beta}\right)=\frac{\{(R-r)+t(1+r)-\beta t(R-r-f)\} x}{2 t(1+r+f)} \\
\Rightarrow & \tilde{x}_{\beta}=x\left(1-\frac{\{(R-r)+t(1+r)-\beta t(R-r-f)\}}{2 t(1+r+f)}\right)
\end{aligned}
$$

Note that $\left(x-\tilde{x}_{\beta}\right) \geq 0$ for $\beta \leq \frac{(R-r)+t(1+r)}{t(R-r-f)}$.

Thus, the compliance on part of the firms is enhanced to the magnitude of,

$\left(\tilde{x}_{\beta}-\tilde{x}_{o}\right)=\left\{\frac{x\{\beta(R-r-f)\}}{2(1+r+f)}\right\} ;$ where $\tilde{x}_{o}=\tilde{x}=x\left(1-\frac{(R-r)+t(1+r)}{2 t(1+r+f)}\right)$ from equation (7).

Similarly, as above,

$$
V\left(\tilde{x}_{\beta}\right)-\pi(x)=\phi(x)-\mathcal{L} ; \phi^{\prime}>0
$$

We have $\left(\mathrm{x}-\tilde{x}_{\beta}\right)<\left(\mathrm{x}-\tilde{x}_{0}\right)$ and for $\beta=0,(8)$ boils down to (6). (8) also states that $V\left(\hat{x}_{\beta}\right)<V\left(\hat{x}_{0}\right)$ and $\hat{x}_{\beta}>\hat{x}_{0}$, as shown in figure 4 below.

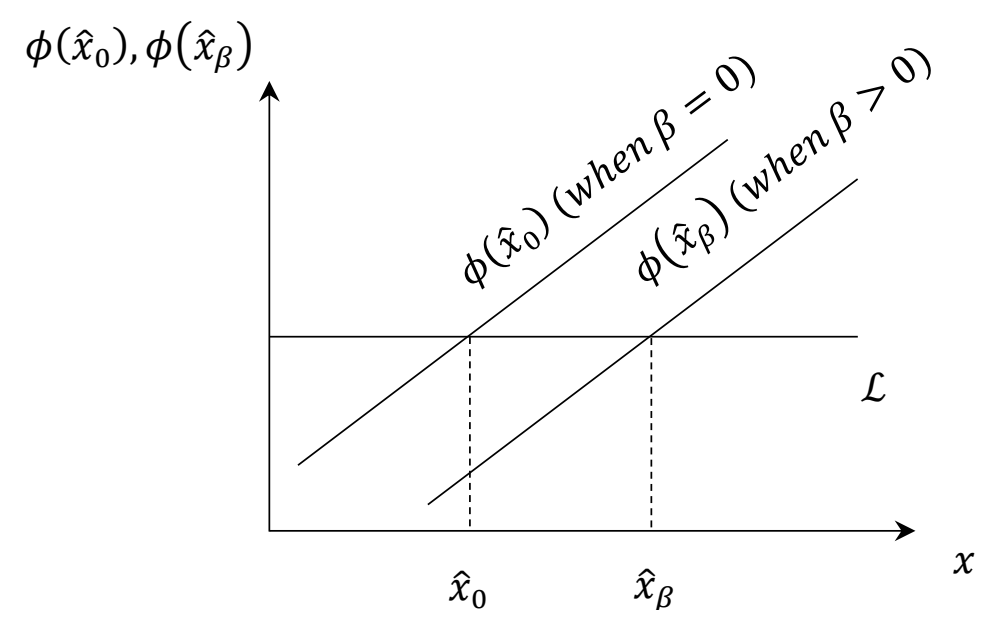

Figure 4: Upfront Fractional Tax Payment and the incentive for false litigation 
Proposition 4: The policy of upfront fractional payment of the litigated tax amount, i.e., $\beta>$ 0 , lowers the value of false litigation for and enhances compliance and better reporting of earnings by the firms.

Proof of Proposition 4: Please see the above analysis in section 4 and figure $4 . \quad$ Q.E.D.

We show that the logic of upfront payment is to control or regulate the incidence of false litigation; $\beta$ improves the reporting of income by the firms to the magnitude of $\left\{\frac{x\{\beta(R-r-f)\}}{2(1+r+f)}\right\}$ which adds to the government revenue in the current time frame and enables it to earn $r$ on it or spend it on public use in the current time frame with a shadow return on the same being greater than $r$, say $\tilde{r}$. In essence, from the government perspective, $\beta$ has positive impact the deliberate usual delays in tax payments by the firms (though its overall impact on the revenue is not unambiguous). ${ }^{4}$

\section{Section 5: The Informal Sector, Welfare and Government Policy}

As we have shown in section 3 that as long as the informal rate of return is more than the formal rate of return, i.e., $R>r$, the firms (even the ones with smaller turnovers (please see figure 3)) will find it rational to engage in false litigation against the government regarding the tax claims and invest in the informal sector, and as a result both the problem of and the ones due to sham litigation get aggravated. In the previous section we have suggested that the problem of sham litigation can be checked by the policy of upfront fractional payment $(\beta)$ of the litigated amount.

Let us analyze the policy response of a welfare maximizing government and its welfare implications. We, as of now, have only thought of the formal sector firms to contest their tax liabilities to buy time and in the meantime invest their unreported earnings in the informal sector and make extra profits to the tune of the rate of return differential between the informal and the formal sectors. The formal sector firms' above activity adversely affects the welfare as the government's tax revenue gets reduced due to non-reporting by the firms of their earnings and at the same time informal activity gets enhanced as the firms invest their unreported earnings in the informal sector. Thus, the main objective of the government is to maximize tax revenues and curb the engagement of the formal sector firms in the informal sector. Let the objective function of the welfare maximizing government be given as the following:

\footnotetext{
${ }^{4}$ We don't exclusively focus on the impact of the proposed policy on the tax revenue (as the impact is not unambiguous), rather the emphasis is on the overall welfare impacts of the policy.
} 


$$
V_{g^{o}}=V_{g^{o}}(S(R(\beta), \beta)) ; S=(x-\tilde{x})
$$

The impact of the policy of the upfront fractional tax payment would be the following,

$$
\frac{\delta V_{g^{o}}}{\delta \beta}=\underbrace{\frac{\delta V_{g^{o}}}{\delta S} \frac{\delta S}{\delta R} \frac{\delta R}{\delta \beta}}_{<0}+\underbrace{\frac{\delta V_{g^{o}}}{\delta S} \frac{\delta S}{\delta \beta}}_{>0}
$$

where, $\frac{\delta V g^{o}}{\delta S}<0 ; \frac{\delta S}{\delta R}>0 ; \frac{\delta R}{\delta \beta}>0 ; \frac{\delta V_{g^{o}}}{\delta S}<0$ and $\frac{\delta S}{\delta \beta}<0$.

As we have already shown in the previous section (section 4) that $\beta=\frac{(R-r)+t(1+r)}{t(1+R)}$ would ensure that $S=(x-\tilde{x})=0$. Let, for the sake of definition, some $\beta_{o}^{*}=\frac{(R-r)+t(1+r)}{t(1+R)}$ optimize the above objective function of the government and ensure that $S=0$. We assume that the second order condition for an optimal and unique $\beta_{o}^{*}$ is satisfied.

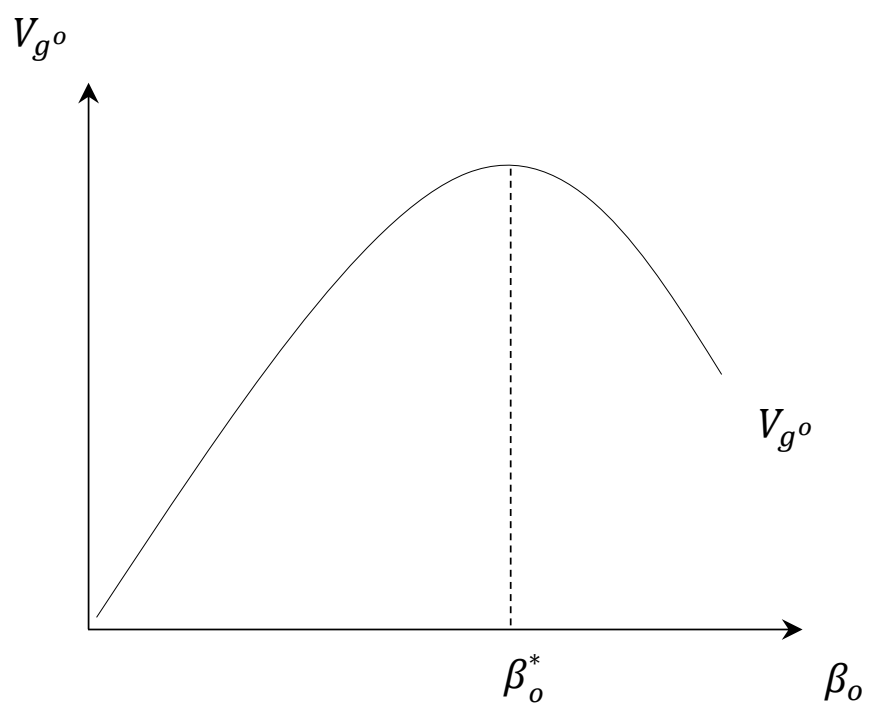

Figure 5: Optimal Upfront Fractional Tax Payment and Welfare

Proposition 5: $\beta=\beta_{o}^{*}$ is the optimal and unique upfront fractional payment of the litigated tax amount that the welfare maximizing government ought to use a policy tool.

Proof of Proposition 5: Please see the above analysis in section 5 and figure 5. $\quad$ Q.E.D.

We suspect that a deeper analysis of the informal sector may generate new insights, which we now attempt to proceed with. Let the informal sector comprise of the poorer firms which can not avail funds from the formal credit markets due to lack of collateral and hence 
they represent the demand side in the informal credit market. As stated above (in section 3), the formal sector firms dispute the tax amounts and litigate against the government in the courts of law for the purposes of investments in the informal sector, lending to the poorer informal sector firms, and in turn earn huge profits as the interest rate in the informal sector, $R$, is greater than that in the formal sector, $r$, i.e., $R>r$. Thus, $(x-\tilde{x})$, the unreported earnings of the formal sector richer firms make up the supply of credit in the informal credit market. As stated above (in section 3), $(x-\tilde{x})=\frac{\{(1+R)-(1-t)(1+r)\} x}{2 t(1+r+f)} \Rightarrow(x-\tilde{x})=\frac{(R-r) x}{2 t(1+r+f)}+\frac{(1+r) x}{2(1+r+f)}$ and $\frac{\delta(x-\tilde{x})}{\delta R}=\frac{x}{2 t(1+r+f)}>0$.

Let us assume that the informal sector firms need credit for production of some good having the price of 1 and uses labour, $L$ as the only input facing $w$ as the wage rate. Let the production function of the informal firm be given by, $q=q(L)$.

The firm's objective function is to maximize profits, which can be written as follows,

$$
\pi=q(L)-w(1+R) L
$$

Optimizing, we get,

$$
q^{\prime}(L)-w(1+R)=0
$$

Let $L^{d}$ be the demand for labor (at the given wage, i.e., $w$ ) at the optimum, i.e., $L^{d}=L^{d}(w(1+R))$. Thus, the firms demand for credit would be $w L^{d}(w(1+R))$. And, let the supply of credit is given by $\bar{S}+S(R(\beta), \beta)$; where $\bar{S}$ is the supply of credit from other sources apart from the richer formal sector firms. Thus, the credit market clearing condition would be as follows:

$$
w L^{d}(w(1+R))=\bar{S}+S(R(\beta), \beta)
$$




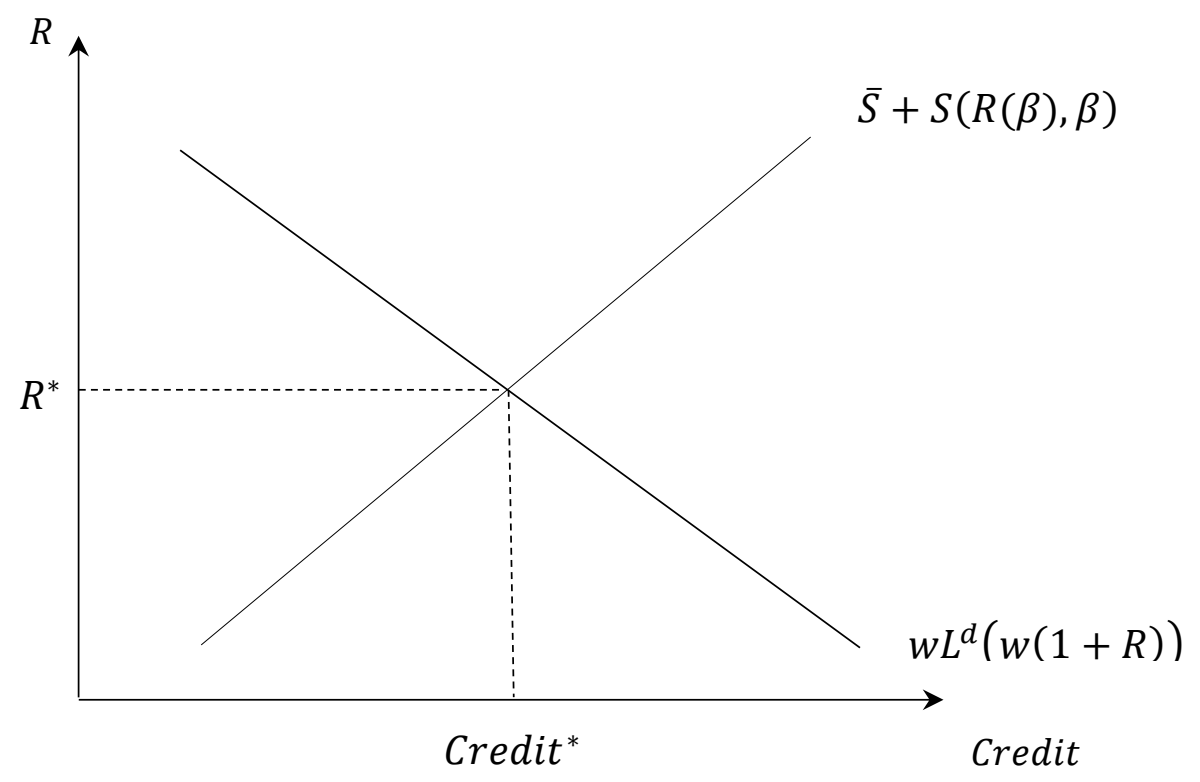

Figure 6: Informal credit market equilibrium

Analysis of the labor market in the informal sector can help us understand better the dynamics of policy making. Let the labor supply be given as $\bar{L}$. We assume full employment in the labor market, i.e., inelastic labor supply.

Thus the labor market equilibrium would be given by the following equation,

$$
L^{d}(w(1+R))=\bar{L}
$$

From (11) we know that, in equilibrium, as $R$ goes up, $w$ must fall, given the labor supply, i.e., given $\bar{L}, \frac{\delta w}{\delta R}<0$. As $R$ goes down, the real wage, i.e., $w$ (as we have normalized $P$ to be equal to 1) goes up, increasing the demand for credit, i.e., $w \bar{L}$.

Thus the demand for labor, i.e., $L^{d}$ is affected by both the labor market as well as the credit market. Thus, (figure 7), the demand for labor curve contains the effects of both, the credit market as well as the labor market, i.e., $L^{d}=L^{d}(w(1+R(w)))$.

Therefore, if somehow $R$ goes up, the real wages of the laborers would fall (through reduced demand for labor (in figure 7), $L^{d}(w(1+R(w)))$ would shift leftwards lowering the wage rate, $w$. The same can be shown as follows (figure 7). 


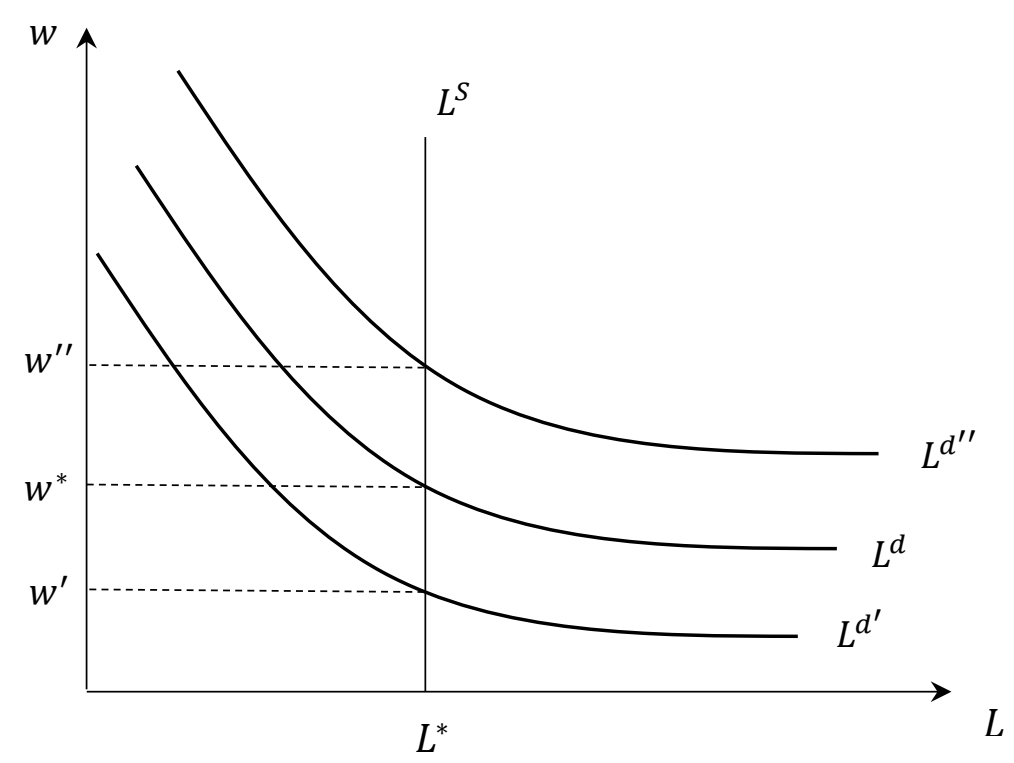

Figure 7: Informal labour market equilibrium

Now, let us consider the objective function of the welfare maximizing government in light of the above discussed activities of the informal sector. It would be as below:

$$
V_{g^{i}}=V_{g^{i}}\{S(R(\beta), \beta), A\}
$$

Where, $A$ reflects the government's concern about the real wages of the laborers.

The objective function of the welfare maximizing government can be rewritten as,

$$
V_{g^{i}}=V_{g^{i}}\{S(R(\beta), \beta), w(\beta)\}
$$

Now, the impact of the policy of the upfront fractional tax payment would be the following,

$$
\begin{aligned}
& \frac{\delta V_{g^{i}}}{\delta \beta}=\frac{\delta V_{g^{i}}}{\delta S} \frac{\delta S}{\delta R} \frac{\delta R}{\delta \beta}+\frac{\delta V_{g^{i}}}{\delta S} \frac{\delta S}{\delta \beta}+\frac{\delta V_{g^{i}}}{\delta w} \frac{\delta w}{\delta \beta} \\
& <0 \quad>0 \quad<0
\end{aligned}
$$

From (9) and (15) it can be seen that $\beta$ has an additional negative impact on objective function of the government. The above said negative impact is on the welfare of the laborers in the informal labor market, in the form of reduced wages. Thus, from the welfare maximizing government's perspective, it would be a matter of concern. 
Also, in the above problem, as can be reasonably expected, the previously optimal $\beta_{o}^{*}$ can not optimize the above function, since the government now has an additional concern in the form of the real wages of the laborers in the informal sector. As has been stated above, $\beta_{o}^{*}$ ensures that $S=0$, implying chocking of the fund availability to the informal firms, resulting in a decline of the wage rates in the informal labor market, hinting at reduced welfare of the laborers to the magnitude of $\left\{\frac{\delta V}{\delta w} \frac{\delta w}{\delta \beta}\right\}$. Since the government cannot work with $\beta_{o}^{*}$, let $\beta_{i}^{*}$ optimize the above function, given the new consideration of the government, i.e., welfare of the laborers in the informal labor market. We assume that the second order condition for an optimal and unique $\beta_{i}^{*}$ is satisfied. Thus, now, given the new consideration of the government, it is necessarily required that the new optimal $\beta$, i.e., $\beta_{i}^{*}$, be less than the older one, i.e., $\beta_{i}^{*}<$ $\beta_{o}^{*}$. The same is depicted below (figure 8).

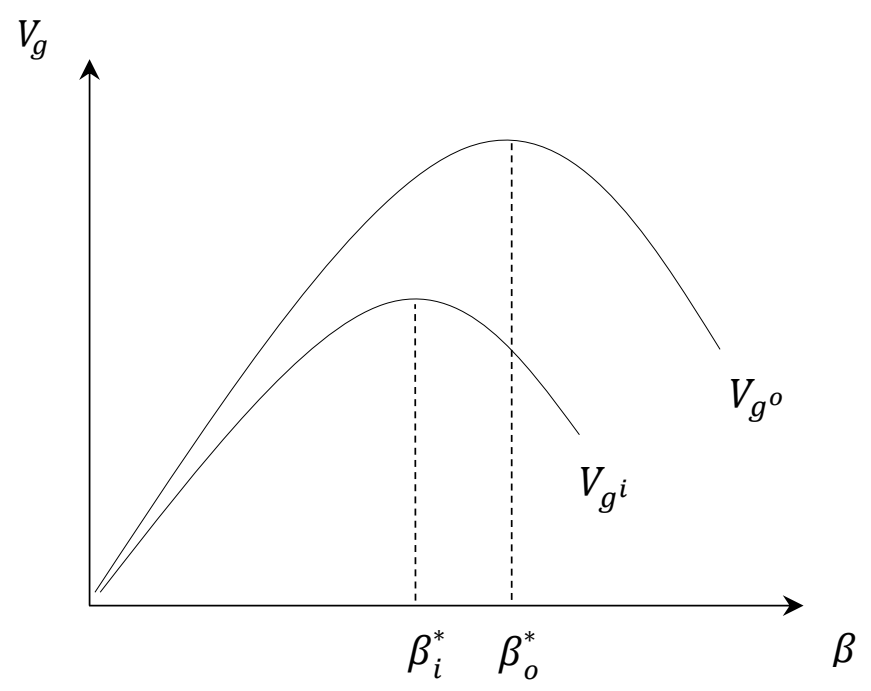

Figure 8: Optimal Upfront Fractional Tax Payment and Welfare

Proposition 6: The new consideration of the government (welfare of the laborers in the informal labor market) shrinks its objective function and necessitates that it chooses $\beta_{i}^{*}<\beta_{o}^{*}$ as the new upfront fractional payment of the litigated tax amount as the policy tool.

Proof of Proposition 6: Please see the above analysis in section 5 and figure 8. $\quad$ Q.E.D.

Literature (Dasgupta and Marjit (2006), Marjit, Mukherjee and Kolmar (2006), Marjit and Kar (2012)) hints that sometimes the government strategically may design its policies 
(weaker governance system) to foster and perpetuate the informal labor markets even at the cost of credibility of the legal jurisdictions/machinery. The justification for this act of the government is that the informal sector provides a social security for the poor through generating employment (at a much lower wage rate relative to the formal sector employment though), which the government is unable to provide directly, and thus, the said act of the government can be understood as an effective tool to counter political unrest. Thus, the informal sector can be thought of being effective in both, reducing unemployment and alleviating poverty.

The key point that we wish to highlight here is that political economy significantly influences policy making/implementation, and the same is more evident in the developing countries due to the huge informal sector that they house. Most countries are democratic and the governments are elected through the process of voting. The firms and the laborers may belong to the formal and the informal sector. These votes, however, are not bifurcated as coming from the formal or the informal sectors. They are of equal importance and have significant impact on the political outcomes.

Every country has the informal sector but the magnitude of the informal sector in the developing countries is huge (about over $80 \%$ in India) in comparison to that of the formal sector. Thus, we are of the opinion that especially in developing countries, the policies of the governments cannot ignore the welfare of the informal sector.

Proposition 7: The government may wittingly choose a level of the upfront fractional payment $(\beta)$ of the litigated amount of the tax to be lesser than the optimal one, in order to allow for informal activity(ies).

Proof of Proposition 7: Please see the above discussion.

Q.E.D.

\section{Section 6: $\underline{\text { Concluding Remarks }}$}

We have taken up a practical policy problem related with tax evasion by firms when they can invest in an informal credit market at higher than the formal rate of interest. This may lead to excessive litigations against the government, delaying tax payments even when firms sell their entire output in the formal sector. Thus, taxation and informal credit market can interact in an interesting way. Inability of the government to recognize the presence of the informal credit market and hence charge an interest penalty opens up an avenue for clandestine deals and protracted judicial settlements further add to the profits of the litigating firms. Note that the government may end up getting the entire initial claim eventually and if the penalty 
inclusive of formal interest rate does not distort the present value of tax payments, firms make a kill just by deferring such payments. To the extent the government cannot invest in the informal sector, it loses revenue. We also propose fractional - payment of the disputed amount as a potential solution to the issues of excessive litigations against the government, delayed tax payments and evasion, which not only takes care of the said problems but also may (it is not unambiguous though) enhance the tax revenue of the government. Finally, by bringing in the analysis of the informal sector (informal credit and labor markets) and the government's concern of the welfare of the agents in the informal sector, we attempt to explain as to why and how the government policies may be intentionally designed for fostering the informal sector.

\section{References}

Acemoglu, D., Johnson, S. \& Robinson, J. A. (2001). The colonial origins of comparative development: An empirical investigation. American Economic Review, 91(5), 1369-1401.

Acemoglu, D., \& Johnson, S. (2005). Unbundling institutions. Journal of political Economy 113(5), 949-995.

Allingham, M. \& Sandmo, A. (1972). Income tax evasion: A theoretical analysis. Journal of Public Economics, 3(2), 323-338.

Benjamin, A. O. \& Pande, R. (2012). Corruption in developing countries. Annual Review of Economics, 4, 479-509.

Blackburn, K., Bose, N., \& Capasso, S. (2012). Tax evasion, the underground economy and financial development. Journal of Economic Behavior \& Organization, 83(2), 243253.

Capasso, S. \& Jappelli, T. (2013). Financial development and the underground economy. Journal of Development Economics, 101(C), 167-178.

Chemin, M. (2010). Does court speed shape economic activity? Evidence from a court reform in India. The Journal of Law, Economics, \& Organization, 28(3), 460-485.

Congleton, R.D. \& Hillman, A.L. (ed.) (2015). Companion to the political economy of rent seeking. Edward Elgar.

Dasgupta, A. \& Mookherjee, D. (1998). Incentives and institutional reform in tax enforcement. New Delhi: Oxford University Press.

Dasgupta, I. \& Marjit, S. (2006). Evasive reform: Informalization in a liberalized economy with wage-setting unions, in Basudeb Guha-Khasnobis and Ravi Kanbur (Eds.), Informal Labour Markets and Development. NY: Palgrave-McMillan. 50-70.

Dhami, S. \& al-Nowaihi, A. (2007). Why do people pay taxes? prospect theory versus expected utility theory. Journal of Economic Behaviour and Organiztion, 64(1), 171-192. 
Kapur, D., \& Mehta, P. B. (2007). Public Institutions in India: Performance and Design. Oxford University Press.

Kapur, D., Mehta, P. B. \& Vaishnav, V. (Eds). (2017). Rethinking Public Institutions in India. Oxford University Press.

Kenyon, T. (2008). Tax evasion, disclosure, and participation in financial markets: Evidence from brazilian firms. World Development, 36(11), 2512-2525.

Klein, C. (1989). The economics of sham litigation: Theory, cases, and policy. Bureau of Economics Staff Report to the Federal Trade Commission.

Loukas, B., Adrian, B., Rudolf, K. \& Matthias, S. (2015). The hidden cost of tax evasion. Journal of Public Economics, 129(C), 14-25.

Marjit, S. \& Mitra, S. (2015). Project report, CTRPFP, CSSSC.

Marjit, S., Rajeev, M., \& Mukherjee, D. (2000). Incomplete information as a deterrent to crime. European Journal of Political Economy, 16(4), 763-773.

Marjit, S., Seidel, A. \& Thum, M. (2016). Tax evasion, corruption and tax loopholes. German Econ Rev. doi:10.1111/geer.12107.

Marjit, S. \& Shi, H. (1918). On controlling crime with corrupt officials. Journal of Economic Behavior and Organization, 34(1), 163-72.

Marjit, S., Mukherjee, A. \& Mukherjee, V. (2000). Harassment, corruption and tax policy. European Journal of Political Economy, 16(1), 75-94.

North, Douglass. (1990). Institutions, Institutional Change, and Economic Performance. Cambridge: Cambridge University Press.

Porta, Rafael La, et al. (1998). Law and finance. Journal of Political Economy, 106(6), 1113 -1155 .

Rodrik, Dani, Arvind Subramanian, and Francesco Trebbi. (2004). Institutions rule: the primacy of institutions over geography and integration in economicdevelopment. Journal of Economic Growth, 9(2) 131-165.

Slemrod, J. \& Keen, M. (2017). Optimal tax administration. Journal of Public Economics, (forthcoming).

Slemrod, J. (2007). Cheating ourselves: The economics of tax evasion. Journal of Economic Perspective, 21(1), 25-48.

Slemrod, J. \& Yitzhaki, S. (2002). Tax avoidance, evasion and administration. In: Auerbach, A.J. \& Feldstein, M. (Eds). Handbook of Public Economics, North Holland Publishers, 1423-1470.

Sokoloff, Kenneth L., and Stanley L. Engerman. "History lessons: Institutions, factors endowments, and paths of development in the new world." The Journal of Economic Perspectives 14(3), 217-232.

Tanzi, V. \& Davoodi, H.R. (2000). Corruption, growth and public finances. IMF Working Paper, 00/182, 1-27.

Xiaoguang S, C. (2017). The effect of a fiscal squeeze on tax enforcement: Evidence from a natural experiment in China. Journal of Public Economics, 147(C), 62-76.

Yitzhaki, S. (1974). A note on income tax evasion: A theoretical analysis. Journal of Public Economics, 3(2), 201-201. 